(C)2010 IEEE. Personal use of this material is permitted. However, permission to reprint/republish this material for advertising or promotional purposes or for creating new collective works for resale or redistribution to servers or lists, or to reuse any copyrighted component of this work in other works must be obtained from the IEEE. 


\section{Teaching Business Process Concepts Using Enterprise Systems in a Globalized Context}

\author{
Bjørn Jæger ${ }^{1,2}$ \\ ${ }^{1}$ Molde University College, Norway \\ ${ }^{2}$ School of Information Systems \\ Curtin University of Technology \\ Australia \\ bjorn.jager@himolde.no
}

\author{
Vanessa Chang \\ School of Information Systems \\ Curtin University of Technology, Australia \\ Vanessa.Chang@curtin.edu.au
}

Amit Rudra

School of Information Systems

Curtin University of Technology

Australia

A.Rudra@curtin.edu.au

\author{
Ashley Aitken \\ School of Information Systems \\ Curtin University of Technology \\ Australia \\ A.Aitken@curtin.edu.au
}

\author{
Berit Helgheim \\ Molde University College, Norway \\ berit.helgheim@himolde.no
}

\begin{abstract}
There is significant growth in global business operations and ERP systems are deemed as important applications in order to unify and improve fragmented and globalised markets. These systems are complex and students struggle to grasp not only the underlying business concepts but also the technology involved. This paper describes the design and implementation of teaching materials for a multinational cross-company collaboration assignment using a commercial ERP system. It includes elements of i) integrated business processes, ii) globalization and iii) experiential learning in Masters courses at two universities - one in Australia and the other in Norway. We discuss the lessons learned from the pilot study including the development of an evaluation tool, inter-university student communication, evaluation of the learning outcome, and the benefits of the cross-country business role play exercise.
\end{abstract}

\section{Introduction}

The development of enterprise systems over the last decades has emerged to be one of the key advancements in the corporate use of information technology. An enterprise system seamlessly supports and automates core organizational business processes by integrating the organization's functional areas and sharing data across the organization in real time. There has been a significant growth in global business operations and organizations are taking advantage of the opportunities and advancement of enterprise system applications to support global operations. One category of such applications is the enterprise resource planning (ERP) systems which supports a range of routine work activities and business processes of an organization. Examples are order management, logistics, distribution, inventory, manufacturing, shipping, invoicing, and accounting. In addition, an ERP system can support other business activities such as marketing, quality management and human resource management [20]. Multinational businesses invest in ERP and other enterprise systems to support their global operations. In reports by AMR Research [3] and the Aberdeen Group [1] conducted by interviewing decision makers predominantly within manufacturing they both found that globalization is the most important business issue organizations plan to address with ERP investments. The importance of globalization by advances in information and communication technologies has resulted in convergence of global enterprise activities like global data access and control of international operations in real time ([6], [9]). ERP systems are considered to be important applications in quest to unify and improve fragmented and globalized markets and their business operations worldwide. Organizations such as Texas Instruments, BHP Billiton, Fonterra, Woolworths, National Australia Bank have all implemented an ERP system to support global operations [9]. According to Cutter Benchmark Review [4], more than $33 \%$ of respondents in a recent survey indicated that they have a global ERP system in place, this is a significant increase compared to the $20 \%$ reported by AMR Research [16] for 2003-2004. ERP systems are suitable for global operations as it encompasses all three tiers of local, national and international business operations complying with financial and legal requirements at each level. Examples of functionalities for global operations that are supported by ERP-systems are that of currency 
conversions, time and location adoption, consolidation across diverse accounting standards and legislations, multilingual facilities, legal control and declarations to the authorities. Globalization has been a primary consideration for large companies, presently even small to medium size enterprises have to address globalization since all companies are challenged by the introduction of lower priced products from countries with inexpensive labour, new offshore manufacturing possibilities, and new global market opportunities. This introduces more complexity to the supply chain which can be handled by ERP systems. The Aberdeen Group [1] found that companies using ERP to streamline workflows across multiple sites gained $66 \%$ more improvement in reducing time from order to delivery compared to others using ERP at selected sites only. The increased complexity by operating in multiple countries is encountered even for internal operations within a company since each country specific division, by law, must operate as a separate legal entity forcing frequent operations like inventory transfer to be treated as purchase and sale.

Given the importance of ERP systems as described above, and the fact that most business graduates will manage or relate to such systems, it is imperative that such concepts are not only taught at the graduate level but also practiced with hands-on assessment tasks in a global context. The main purpose of this paper is to describe the development of a curriculum addressing these needs.

The remainder of this paper describe our motivation in Section 2, followed by how the teaching method encompasses experiential learning theory in Section 3. Section 4 outlines the curriculum content while Section 5 describes the method used to develop the curriculum by doing a pilot and full scale study. In Section 6 we describe how we develop a pre- and postsurvey tool. Section 7 discusses lessons learned from the pilot study and it gives recommendations for the upcoming full scale study. Finally, Section 8 provides a summary.

\section{Motivation}

Due to the increasing importance of ERP systems worldwide universities are obligated to embed ERP into their curriculum. Given the complexity of ERP applications and the difficulty in grasping the concepts of ERP, students ought to be given the opportunity to experience the use of an ERP system in a globalized environment. This may be done with hands-on experience and interaction with fictional transnational organizations. In this regard, students will be able to work through the types of transactions that would take place in a real setting. This innovative teaching and learning experience is a working example of collaboration between academia and industry. The success of this teaching method has direct implications for graduates' employability and their job readiness for industry [10]. Another motivation to embed ERP into university curriculums is one that addresses the worldwide skills shortage in IT and specifically in ERP related skills. For example, SAP recently reported that a global shortage of 30,000 to 50,000 skilled SAP professionals is expected in coming years [23]. To meet growing demand for ERP professionals, companies such as SAP developed and implemented a SAP University Alliances Program (UAP) that helps prepare students for IT careers and providing instructors with training and professional development opportunities. The SAP UAP provides universities with curriculum and SAP certification resources operating in a software environment that is identical to the SAP systems used by businesses [20]. About 400 universities worldwide were reported to have incorporated SAP in their business curriculum [11].

A further motivation is the major downturn in enrolments faced by computing related educational programs ${ }^{1}$ since the dot-com collapse in 2000 . This has caused deep concern not only to those directly affected at university programs but also to educational institutions, employers and politicians. These changes demand evaluation and modification of education programs. Challenges include the move towards programs that are more applied, more professionallyoriented and of more international character ([8], [12], [19]). Demand is expected to grow for subjects such as enterprise systems and business process management producing graduates with knowledge of coordinating complex information and supply chain networks and project managers managing global IT projects [12]. In particular, it is a call for more focus on teaching students how to think beyond information silos possibly at the cost of a reduction of specific disciplinary skills. Suggestions for how to approach this include strengthening the curriculum in relation to the integrated nature of business processes, globalization and experiential learning [8]. The Joint ACM/AIS Undergraduate Curriculum Revision Task Force has addressed the problem by giving recommendations for new courses including a Business Process Management course about which they said: "The demonstration of leading ERP systems such as SAP and their use in business process management is highly recommended." [2].

\footnotetext{
${ }^{1}$ Computing related programs include Computer Science, Informatics, Information Science, Information Systems, and Information Technology.
} 
Finally, although, there has been much research undertaken in the area of teaching ERP concepts [21], research into its teaching in a globalized context have been far and few. It is our endeavour to contribute towards this need.

\section{Experiential Learning}

David A. Kolb ([15], [22]) created a model of the four stages: concrete experience, observation and reflection, the formation of abstract concepts and testing in new situations. These were presented in an experiential learning cycle as illustrated in Figure 1. This experiential learning process can be seen as a learning spiral where the learner is brought to a new level of understanding each time the cycle is completed. Specifically we address this by forming the student assignment as follows. In the first step of concrete experience, each student plays a dedicated business role using the SAP system to perform a given business operation. In step 2 of observation and reflection, each student must document the feedback received on the operations performed in the form of SAP system messages and e-mails from the collaboration partner in the business process. In step 3 of forming abstract concepts, the student documents what has been done by developing a Business Process Model of the actions.

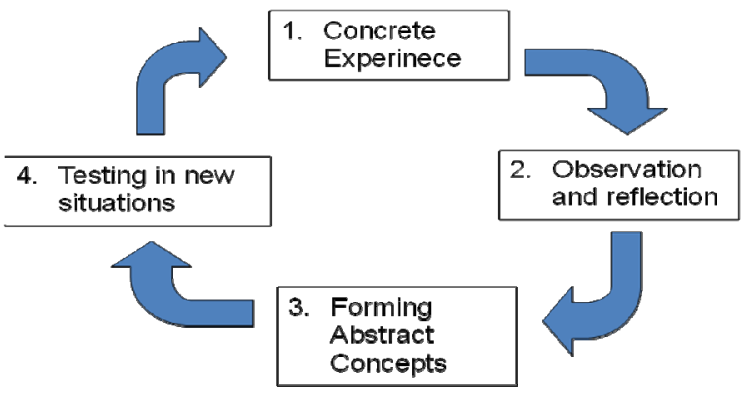

Figure 1. Experiential Learning Cycle [22]

In step 4 , when completing the first cycle, the student is given another business role before conducting the same business operation again. By completing several cycles with varying roles, students get hands-on experience in various business situations which will contribute to learning the integrated nature of the business processes conducted.

\section{Integrated Business Processes Curriculum}

The theory of business processes and the practice of using SAP were integrated into existing Master level units (courses) at each of the universities in Australia and Norway. This new curriculum is designed to bridge the gap between theory and practice by giving students experience of performing business transactions for a company. For many companies, such transactions may take place in a globalized setting. This curriculum aims to provide students with the skills to holistically consider an integrated business model by combining business processes, globalization and experiential learning [8]. It is hoped that this integration will enable students to learn an organization's business activities across functions, business units and geographical areas ([6], [14]). It is envisioned that the students will leverage the experience through this collaborative learning process and develop business skills to effectively cope with today's global competitive environment. As discussed in Section 2, not only are organizations investing in ERP systems but they are also recognizing the importance of consolidating and integrating their international operations. The new curriculum was also developed with this in mind. This new curriculum and the sales order business role-play between students from the two universities are presented in this section.

\subsection{Global Bike Inc}

The hands-on exercises are based on a preconfigured model enterprise called the Global Bike Incorporated (GBI) provided by the SAP UAP. GBI has preconfigured 100 identical Bike America companies as shown in Figure 2. Each student is given the responsibility of one such preconfigured company. By using the company setup each student can run business processes individually for their own Bike America company even if all companies are configured on the same physical SAP server.

\section{Enterprise Structure for Curtin University}

(SAP Client 240)

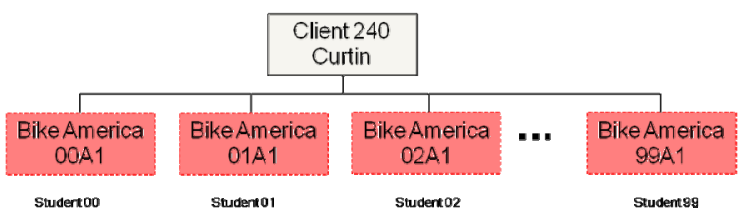

Figure 2. Enterprise structure in SAP ERP system

\subsection{Collaborative Cross Country Assignment: Sales Order Processing}

As illustrated in Figure 3 a sales order business process role play was developed for a cross company setup in which students collaborate in pairs to do the purchasing (SAP Customer Exercises) and sales (SAP Vendor Exercises). The customer company run by one student is purchasing from the vendor company run by 
another student. The vendor company responds to the purchase order by doing the sale, picking and delivery before issuing an invoice to the purchaser. The purchaser receives the goods and pays the invoice.

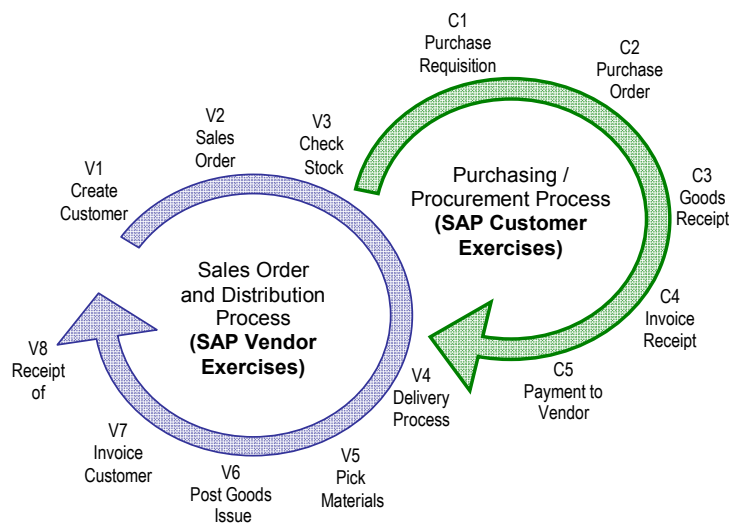

Figure 3. SAP Vendor and Customer Process Integration exercises

In the first part of the assignment (Table 1) the students complete the four steps in Kolb's learning cycle [15]. In the second part of the assignment the students swap roles and run the four steps of Kolb's cycle again.

Table 1. Action Steps in the Sales Order Business Process Assignment. The steps numbered 1-4 correspond to the steps in Kolb's learning cycle [15].

\begin{tabular}{|l|l|}
\hline $\begin{array}{l}\text { Prelim } \\
\text {-inary }\end{array}$ & $\begin{array}{l}\text { Prerequisites: As a student you are teamed } \\
\text { up with another student. You play the roles } \\
\text { assigned by the teacher. }\end{array}$ \\
\hline Step 1 & $\begin{array}{l}\text { Run Exercises: If you are a Vendor, do the } \\
\text { SAP Vendor Exercises, and if you are the } \\
\text { corresponding Customer you do the SAP } \\
\text { Customer Exercises (see Figure 3). }\end{array}$ \\
\hline Step 2 & $\begin{array}{l}\text { Write Log: Write a log containing the SAP } \\
\text { System messages given for each Save- } \\
\text { operation and include a copy of e-mails } \\
\text { exchanged with your partner. }\end{array}$ \\
\hline Step 3 & $\begin{array}{l}\text { Draw a Business Process Model: Draw a } \\
\text { Business Process Model for the Cross } \\
\text { Company Sales Order Processing done in } \\
\text { this exercise. }\end{array}$ \\
\hline Step 4 & $\begin{array}{l}\text { Swap Roles with your partner: Swap } \\
\text { Customer and Vendor roles and run Step 2 } \\
\text { and Step 3 again. }\end{array}$ \\
\hline Final & $\begin{array}{l}\text { Hand in: customer and vendor logs from } \\
\text { Step 2, Business Process Models from Step } \\
\text { 3, and answers to questionnaires }\end{array}$ \\
\hline
\end{tabular}

The communications between customer and vendor companies are illustrated in Figure 4.

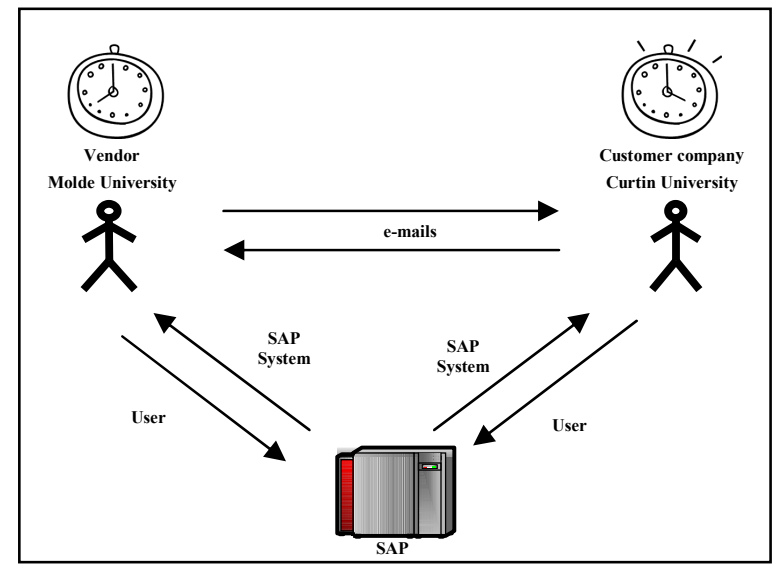

Figure 4. Communications between customer and vendor companies. The role of a customer is played by a student in Australia and that of a vendor by a student in Norway.

Figure 4 also shows a setup of two companies both running on the same physical SAP ERP server hosted at Queensland University of Technology in Brisbane. Communications between the companies in the form of sales order invoicing, purchase order, invoice payment and acknowledgement are effected via e-mail external to SAP. E-mail is used instead of the internal SAP messaging system since the collaborating students were in different time zones with eight hours apart from one another. By using email, the participants do not need to log on to the SAP system to receive business messages.

The SAP Customer and Vendor exercises are explained here to give context of the business process integration exercises conducted by the students of the two universities. The SAP Customer exercises (see also Figure 3) entail that a purchase requisition (C1) and purchase order $(\mathrm{C} 2)$ be created for the vendor. The students posing as Customers send the purchase order (C2) via email to the students playing the role as Vendors. The students were informed that the acceptance of the purchase order by the vendor creates a legally binding contract between the two parties. Figure 5 shows an extract of the purchase order exercise. See Jæger, Rudra, Aitken, Chang, Helgheim (2009) for the complete set of exercises.

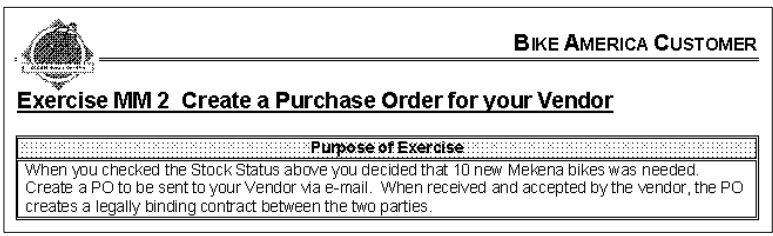

Figure 5. SAP Customer Exercises - Purchase Order (C2)

When the items requested in the purchase order arrived from the vendor, the stock items in the 
inventory must be updated. A Goods Receipt (C3) document must be created to ensure that the products ordered are received within the timeframe requested and in good condition (see Figure 6).

\begin{tabular}{|c|c|}
\hline $\begin{array}{l}\text { (4) } \\
\text { Exercise I }\end{array}$ & MM 4: Create a Goods Receipt \\
\hline \multicolumn{2}{|c|}{ 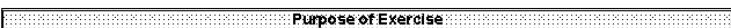 } \\
\hline \multicolumn{2}{|c|}{ 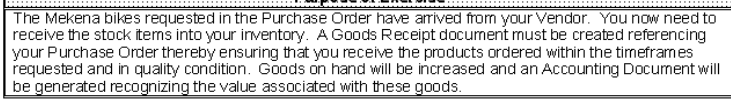 } \\
\hline memurath & $\begin{array}{l}\text { Logistics } \rightarrow \text { Materials Management } \rightarrow \text { Inventory Management } \rightarrow \\
\text { Goods Movement } \rightarrow \text { Goods Receipt } \rightarrow \text { For Purchase Order } \rightarrow \\
\text { GR for Purchase Order (MIGO) }\end{array}$ \\
\hline \multicolumn{2}{|l|}{ Trans Code } \\
\hline \multicolumn{2}{|c|}{ The Goods Receipt $P$ urch ase Order screen appears. } \\
\hline \multirow[t]{2}{*}{ Chec: } & that GR goods receipt 101 appe ars at the right in the He ader. \\
\hline & 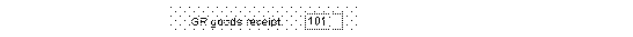 \\
\hline \multicolumn{2}{|c|}{$\begin{array}{l}\text { 2. Type your Purchase Order number in the Purchase Order field. You can find it in the } \\
\text { e-mail you sent with the } \mathrm{P} \text { urchase Order ta the Vendor. }\end{array}$} \\
\hline & 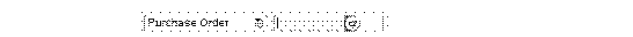 \\
\hline
\end{tabular}

Figure 6. SAP Customer Exercises - Goods Receipt (C3)

In Invoice Receipt (C4), an invoice for payment is received via an email. In this exercise, the invoice payment is posted in an existing general ledger expense account as an account payable to the vendor. Once the expense account is entered, a payment (Payment to Vendor C5) will be issued to the vendor to settle the account. A journal entry is made to the vendor and its account payable; and to the bank cheque account in the general ledger. Figures 7 and 8 show an extract of the exercises for Invoice Receipt (C4) and Payment to Vendor (C5).

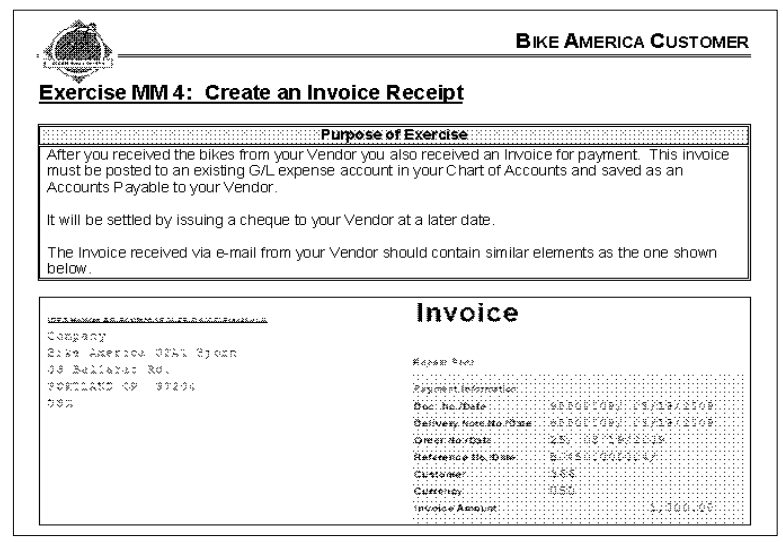

Figure 7. SAP Customer Exercises - Invoice Receipt (C4)

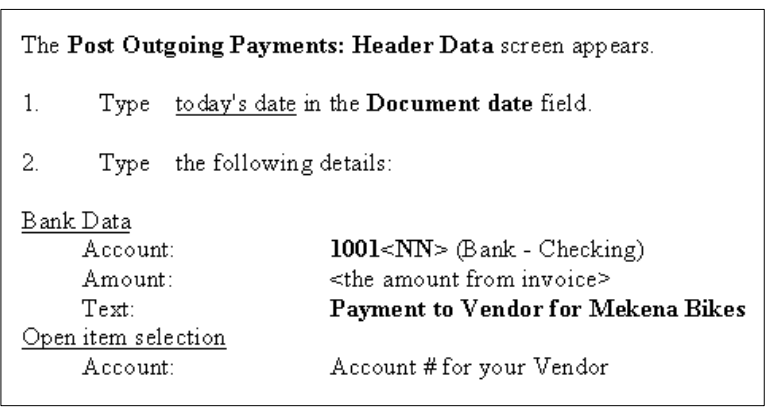

Figure 8. SAP Customer Exercises - Payment to Vendor (C5)

The SAP Vendor exercises begin with creating a master data for a new customer. Information about the customer's shipping, delivery and payment details are recorded. Figure 9 shows an extract of the exercise. From this, a Sales Order is created followed by a Delivery process. The process also includes checking the availability of stocks (V3) and a review of the Availability to Promise (ATP) data. The ATP was used to confirm that the material requested could be delivered by the requested delivery date. The ATP quantity is calculated from the warehouse stock, the planned inward movements of stock and the planned outward of movement of stock.

Following stock checking (V3), a delivery document (V4) is created to commence the shipment for the sales order (V2). The picking materials (V5) process will take place according to the information on the delivery document (V4) - see Figure 10. When the materials are picked for the sales order, the goods leave the plant shipping point to reach the customer's shipping destination (see Figure 11).

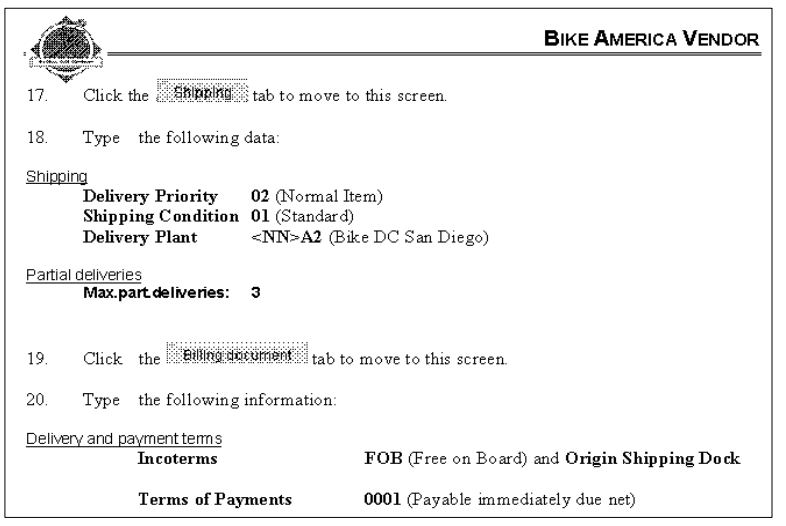

Figure 9. SAP Vendor Exercises - Create Customer (V1)

Exercise SD 9: Start Delivery Process: Create Delivery Documen

Punpose of Exersise You have created a Sales Order. You now need to create a Delivery Document to initiate the shipping
and transpontation activities for this Sales Order. When a Delivery Document is created, the system redetermines the Stock Availability and the quantity of ordered iterns are placed in a Scheduled for Delivery statis

Figure 10. SAP Vendor Exercises - Delivery Process (V4) 


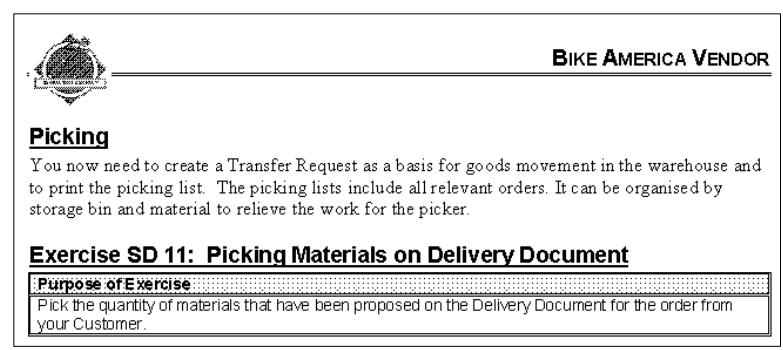

Figure 11. SAP Vendor Exercises - Pick Materials (V5)

The inventory control function of the system will reflect that the materials are no longer available in stock at the time, also known as post good issue (V6). The goods have to be paid for (V7) once they were issued (V6), and a billing document is created to perform this function. When the customer pays for the goods, the vendor creates a payment receipt (V8) to settle the bill. Figures 12, 13 and 14 show extracts of Post Goods Issue (V6), Invoice Customer (V7) and Receipt of Payment (V8) respectively.

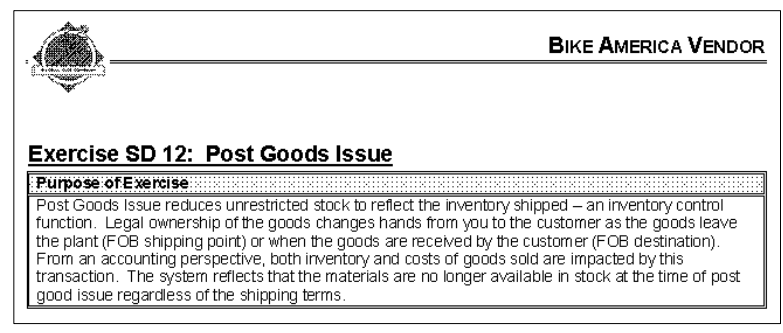

Figure 12. SAP Vendor Exercises - Post Goods Issue (V6)

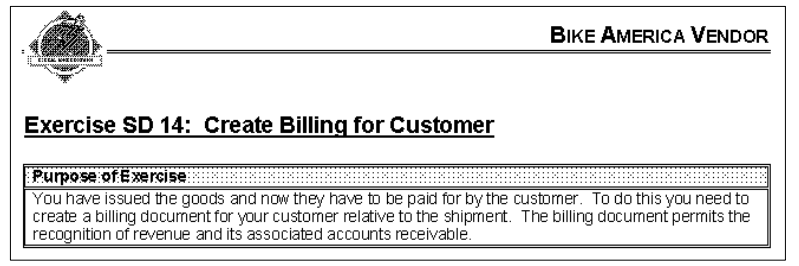

Figure13. SAP Vendor Exercises - Invoice Customer (V7)

\section{Exercise SD 16: Post Receipt of Customer Payment}

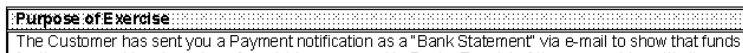
The Customer has sent you a Payment notification as a "Bank Statement" via e-mail to showi that fú
for the payment has been transferred. You now need to P'ost a Receipt of the payment to settle the billing. A joumal entry is made to Accounts Recelvable for you Customer and to the bank checking account in the $G M$.

Figure14. SAP Vendor Exercises - Customer Receipt (V8)

\section{Pilot Study, Full Scale Study and Full Incorporation in Curriculum}

Running an international collaboration assignment is a complex task involving students and teachers in two countries with eight hours time difference, both parties using a common ERP system located at a third location. Since this setup contains many new issues we decided to do initial investigations by running a pilot study to gain experience on the test technical setup, the individual exercises, and the questionnaire developed to evaluate the assignment. Based on this experience we will adopt the assignment and run it again in a full scale study together with a new evaluation which will be used to make a course assignment for full incorporation in the curriculum. This is illustrated in Figure 15 below.

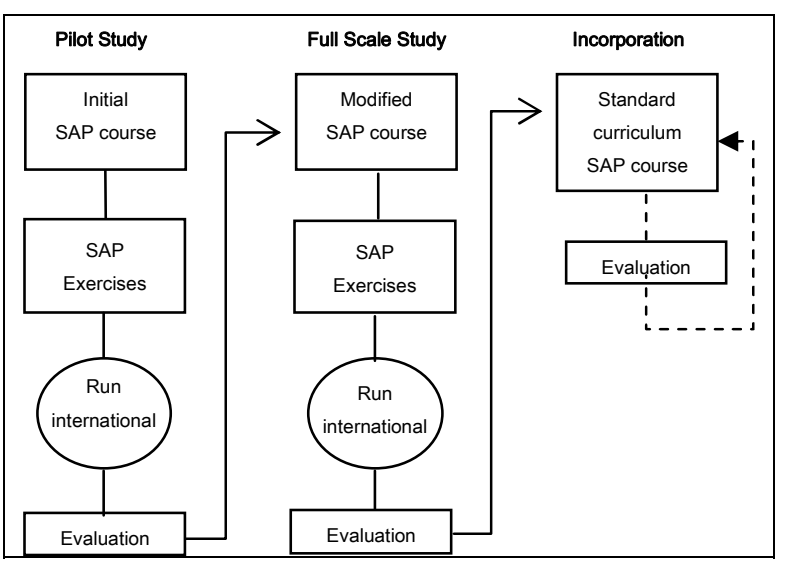

Figure 15. The development of the business process role play assignment conducted in three phases

\section{Evaluation Tool}

In order to run the development process as shown in Figure 15 we needed an evaluation tool. Developing such a tool is not straight forward given the distributed set up, the number of partners involved and the ongoing development of exercises, setup of labs, communication methods, learning goals and so forth. This called for a similar approach for developing the evaluation method as for the development of the assignment itself. Thus, as part of this project we decided to do a small research project with the goal to develop an evaluation tool. In this section we describe the first version of a 7 point Likert scale pre- and postsurvey tool (see Table 2), and how we used this tool in the pilot study to get feedback on the SAP exercises and to get feedback on the evaluation tool itself. Note that since our goal for the pilot study was to get the logistics in place and to start developing the evaluation tool, we did not analyze the detailed results from the pilot study. The primary use of the results was for us to get feedback on the appropriateness of the evaluation tool itself. 
Table 2. Instrument used for International Inter-Group Study (adapted from Seethamraju, 2007)

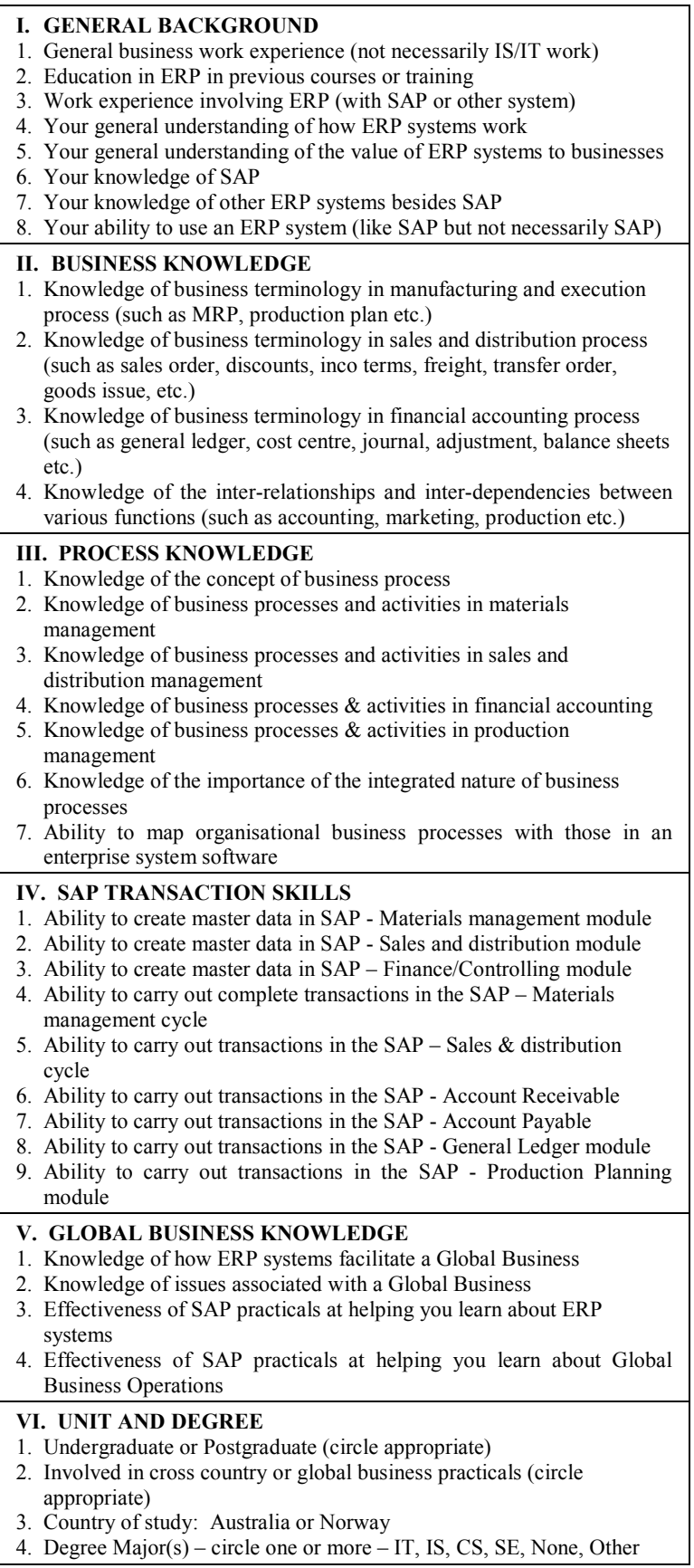

As a starting point a simple survey was chosen as a method for collecting the pre- and post-survey evaluation data. We decided to ask the student to evaluate their own knowledge of business processes and ERP systems, and SAP skills in particular before the unit was undertaken and then again after the unit was completed. The responses from the students were collected and some interesting findings are reported in the next section. We acknowledge that an individual perception of their knowledge and skills may be different from their actual knowledge and skills. The student's grades in the assignments and final examination will also be available to the researchers, so it will be possible to compare their perceptions with a different perspective provided by their grades. For this pilot study we wanted as few students as possible to participate, but at the same time enough students for us to get valid feedback on the pilot test. Again, since our aim with the pilot study was to develop the assignment and evaluation tool, and not to focus on the learning outcome. Thus we asked for eight volunteering master students; four from Norway and four from Australia forming four pairs. The survey instrument itself was based on a survey used in another such study conducted at Sam M. Walton College of Business, University of Arkansas, USA (Cronan et al 2008). Some changes were made, primarily leaving out some questions that were unnecessary as well as some minor changes in the language of the questions, leaving the core of the survey the same. The hope here is that, at a later stage, some comparison can be made with the preceding study.

As mentioned above we did not gain statistically significant results in this pilot since it is primarily to test the processes, procedures and instrument. In particular, the number of students participating in the cross-country assignment was only eight. In the next phase all of the students will participate in the crosscountry assignment. The current group can be considered a base-line or control group.

Ethics clearance was obtained from one of the Universities for the use of students in the research project by submitting the proposed protocol, the survey questions and the research information sheet to an Ethics Approver. The protocol required that we inform the students about the research and, in particular, that the lecturers and unit coordinator did not see the raw data of the research until the students' final unit grades were submitted. Also the raw data will be kept with the School for five years and then destroyed.

All students were surveyed before they commenced the practical work and then again after they had completed the practical work. The surveys asked the student to report on their perceptions of their knowledge of various topics related to ERP systems and SAP, and their experience and skill in using ERP systems and particularly SAP. Paper-based surveys were used in Australia, whereas in Norway the students completed a survey within a MS Word document. The survey consisted of 36 questions broken into the following sections: 1. General Background (8 questions), 2. Business Knowledge (4 questions), 3. Process Knowledge (7 questions), 4. SAP Transaction Skills (9 questions), 5. Global Business Knowledge (4 
questions) and 6. Unit and Degree (4 questions). All the questions in sections one to five used a seven-point Likert scale (None / Very Low, Low, Somewhat Below, Average, Average, Somewhat Above Average, High, Very High). Section six includes questions with specific categories e.g. as to whether the student was undergraduate or postgraduate.

Only very preliminary data analysis has been performed so far and we mention interesting findings in the next section. The main aim of this phase was to trial the teaching materials and the evaluation tool as such to identify any issues within either. The lessons learned and recommendations are the subject of the following sections.

\section{Lessons Learned and Recommendations}

Our greatest concerns were how to handle the logistics of the multi-national setup with communication among students and teachers in different time zones and how to measure the learning outcome in a reliable manner with the evaluation tool. Here we summarize our lessons learned and recommendations towards these goals to be used as input the development of the upcoming full scale study.

\subsection{Lessons Learned}

7.1.1 Inter-university student communication via e-mail. To support the communication among the partners several collaborative tools exists including videoconferencing, virtual worlds, internal collaboration tools in SAP, chat and e-mail. Since we operated the companies via a common SAP server we specifically considered the SAP tools but e-mail was considered more suitable for these business operations. The need for communication when doing business operations depend on the task at hand. For highly standardized frequent operations like purchasing and sale, messages should be exact in conveying the specific information needed to complete the business operation. For purchasing and sale this is Purchase Order, Invoice, Invoice Payment and confirmations. More complex collaborative tasks require richer communication media supporting socialization among partners. For instance one situation might be handling the business disruptions caused by one company taking over another company. This would require a communication media supporting students to collaborate to streamline their processes for the merged company. Since our task in this assignment is purchasing and sale we use standardized specific email for inter-company communication forcing the students to focus on the business operations to satisfy their external partner. Using e-mail also helps to handle timing issues due to partners operating in different time zones since the partner only need to $\log$ on to the common SAP system when a business message requires the partner to do so.

7.1.2 Observations from students. Upon completion of their assessment tasks, but before their grading, two of the students from Norway made positive statements via e-mail to the instructors and one student from Australia made verbal comments (all without being asked). We include the comments to show that these students found this to be an engaging way of conducting the assignment:

- Student A: "I think this case gave a much better understanding than what we have been doing in our ERP course. It's much easier to understand the different operations and how they interact with each other when they are separated, and done by different persons, playing the different actors in a supply chain. I would recommend this kind of work as a way of learning these systems in the future."

- Student B: "In general the exercises have given very good insight to the system, and an interesting approach to learn the system. Aspects like having to take into account the problems arising of different time zones and being dependent of another part to fulfil its tasks before we can carry out our tasks."

- Student C: "Working with students at a remote location has helped understand the business process side of things enormously. Can't all other students have such opportunity of working with inter-university partners located at a remote place with just email as the only means of communicating?"

7.1.3 Observations by the instructors. As the assignments are still being graded, one point that has come to the fore is that those students who participated in the intervarsity role play exercise have performed better and have shown better understanding of the transactional aspects of the sales order processing etc. while those working locally have had some issues in the clarity of these concepts. The likely reasons for this seem to be:

- Those working with inter-university partners spent much more time with their exercises: they had to wait till their partners could post items such as - invoices, purchase orders and payments for transactions.

- Having faced difficulties of being in another time zone those working with inter-university partners 
they had to work on their own to figure out how to organize their work better to avoid or reduce thee incidences of further problems when their roles as customers and vendors were reversed.

- The time lag also allowed such students reflect more upon the problem at hand.

- The separation of tasks enforced by distributed operations helped to clarify the operations and how they are integrated to complete the business process.

\subsubsection{The difficulties with Pre- and Post-Testing}

The pre- and post-survey data from the students indicated that their knowledge and skills in certain areas had decreased across the teaching period. It is unlikely that the teaching and practical work had made the students more confused. What is more likely, or one possible explanation, is that they had forgotten what value they entered into the pre-survey for particular questions and mistakenly entered a lesser value in the post-survey.

7.1.5 The difficulties with Self-Evaluation of Knowledge and Skills. Another explanation for the result mentioned above of an indication of a decrease in competency could relate to the use of self-evaluation of knowledge and skills. It could be that after doing the unit the students re-evaluated their perception of their pre-unit knowledge and skills. Unfortunately, in the way the survey was run with a distinct pre-survey and a distinct post-survey there was no way for the students to re-adjust their pre-survey evaluations as a result of what they had learnt they did or didn't know. So a lesson was learned with regards to the difficulty of self-evaluation of knowledge and skills.

This view is also supported by (Pratt, McGuigan, \& Katzev, 2000) which finds that respondents often overestimate their level of knowledge on a particular subject when using the traditional pre-survey then postsurvey. They find that taking part in a program may show participants that they actually knew much less than they originally reported on the pre-survey. Thus, for such cases they report that pre-survey / post-survey comparisons are misleading because participants use a changed frame of reference to classify themselves after engaging in the program.

To alleviate this problem, another approach is to adjust the testing method to use the retrospective presurvey method to measure change. i.e. the participants are asked to respond to questions about how much they perceived they knew about a particular issue after they have completed the assignment, before they are asked the post-survey questions (Davis 2003). Another way, of course, is to use both of these approaches, i.e. a before pre-survey and an after pre-survey. In this way, we can obtain an understanding of how the students' perception of their pre- knowledge and skills has changed as well.

\subsection{Recommendations}

Based on our findings from the pilot study we will make adjustments and enhancements for future implementation of the globalization assignment as indicated in the lessons learned section. In addition, we would like to point out the following issues:

\subsubsection{Include SAP Foreign Trade Exercises}

To further address global business issues we recommend to include additional exercises using the Foreign Trade and Customs application by SAP. This application is integrated with purchasing by Materials Management to handle imports, with Sales and Distribution for exports, and it is also integrated with Financial Accounting for posting import purchases and export sales. In order to handle the increased complexity, students should run the more simple crosscountry exercises developed in the pilot test first, then they are ready for more realistic foreign trade exercises together with lectures on foreign trade issues.

\subsubsection{Same Survey Sheet for Pre- and Post-Testing} In response to the lessons learned from 7.1.4 with the difficulties with Pre- and Post-Testing it is recommended that the students use the same survey sheet to enter their pre- and post-survey evaluations using a different symbol for each on the survey sheet.

7.2.4 Re-evaluate pre-unit knowledge. Regarding 7.1.5, the difficulties with Self-Evaluation of Knowledge and Skills it is recommended that the students evaluate their knowledge and skills prior to the unit, and that they also re-evaluate their pre-unit knowledge and skills after the unit together with evaluation of their post-unit knowledge and skills.

7.2.5 Consider collaborating with other universities on ERP for global business. Other universities being members of SAP University Alliances have used the SAP environment to address global business issues. The Kelly School of Business in US collaborate with Brandenburg Technical University in Germany on how to streamline business operations in merged companies running SAP (SAP INFO 2007).

\section{Summary}

We have shown that the globalization trend in business creates a growing demand for knowledge on business operations complying with financial and legal requirements in an international context. We address 
this need by creating a course unit that are professionally-oriented and of international character with both practical hands-on experience as well as theoretical lectures. We have completed an initial set of exercises that was well received by the students participating, and it gave us valuable experience regarding how the exercises were set up, the actual contents and how the learning outcome should be evaluated. This will be used in the upcoming full scale study to improve the quality of the assignment.

\section{References}

[1] Aberdeen Group (2007), "The Role of ERP in Globalization," The Aberdeen Group, February 2007.

[2] ACM/AIS (2008), "Business Process Management Course Description," Joint ACM/AIS Undergraduate Curriculum Revision Task Force, Draft - Dec, 2008, http://cis.bentley.edu/htopi/BPM_IS2008_Elective.pdf

[3] AMR Research. (2006) “The Enterprise Resource Planning Spending Report,” AMR Research Inc. 20062007.

[4] Caruso, D. J. (2009) "The Global ERP Backbone Is Becoming an Industry Standard," The Cutter Edge Newsletter, Cutter Consortium, 7.April 2009.

[5] Cronan, T.P., D. E. Douglas, P. Schmidt, O. Alnuaimi (2008) "Using an ERP Simulation Game: Learning and Attitudes toward SAP (Draft Report - ERP Student Sample)" Ref. ITRI-WP123-1008, 10.07.2008, Sam M. Walton College of Business, Univ. of Arkansas, USA.

[6] Davenport, T.H. (1998). "Putting the Enterprise into the Enterprise System," Harvard Business Review 76(4), 121-131.

[7] Davis, G. A. (2003). "Using a Retrospective Pre-Post Questionnaire to Determine Program Impact", Journal of Extension, Vol 41, No 4, August 2003. http://www.joe.org/joe/2003august/tt4.php.

[8] Harvard (2008). Harvard Business School Discusses Future of the MBA, Harvard Bulletin http://www.exed.hbs.edu/cgi-bin/wk/6053.html

[9] Hawking, P. (2007). "Implementing ERP Systems Globally: Challenges and Lessons Learned for Asian Countries," Journal of Business Systems, Governance and Ethics, Vol. 2, No. 1.

[10] Hawking, P., B. McCarthy, A. Stein (2005). "Integrating ERP's Second Wave into Higher Education Curriculum," PACIS 2005 Proceedings. http://www.pacis-net.org/file/2005/178.pdf
[11] Hawking, P., B. McCarthy, A. Stein (2004). "Second Wave ERP Education," Journal of Information Systems Education, Fall 2004.

http://findarticles.com/p/articles/mi_qa4041/ is_200410/ai_n9464916?tag=rbxcra.2.a.2

[12] Helfert, M. (2008). "Business Informatics: An Engineering Perspective on Information Systems," Journal of Information Technology Education, Vol. 7. 2008.

[13] Jæger, B., A. Rudra, A. Aitken, V. Chang, B. Helgheim (2009). "International Collaborative ERP Education: Development of SAP Exercises and an Evaluation Tool," Working Paper/Arbeidsnotat 2009:01, ISBN 978-82-7962-115-7. Molde University College, Norway.

[14] Klaus, H., Rosemann, M. and Gable, G.G. (2000). What is ERP? Information Systems Frontiers 2(2), 141-162.

[15] Kolb, D. A. (1981) "Learning styles and disciplinary differences," in A. W. Chickering (ed.) The Modern American College, San Francisco: Jossey-Bass 1981.

[16] Locke, B, Shepherd, J., and Davis, W. (2005) "The Enterprise Resource Planning Spending Report: 20052006." AMR Research, 17 November 2005.

[17] Pratt, C. C., McGuigan, W. M., \& Katzev, A. R. (2000). Measuring program outcomes: Using retrospective pretest methodology. American Journal of Evaluation, 21, 341-349.

[18] SAP INFO. (2007). "Leaving the Ivory Tower," The SAP Magazine, Issue 147, September/October 2007. http://www.sap.com/about/citizenship/pdf/Education Meets_Practice.pdf

[19] SAP Spectrum (2009) Serving Global Markets Locally, SAP Spectrum Magazine http://www.spectrum.sap.info/ magazine/2009_03_sap_spectrum_en_screen.pdf

[20] SAP UA. (2008) SAP University Alliances http://www. sap.com/about/citizenship/education/universityalliances.epx

[21] Seethamraju, R. (2007). Enterprise Systems (ES) Software in Business School Curriculum - Evaluation of Design and Delivery. Journal of Information Systems Education, Vol. 18(1), 2007, 69-84.

[22] Smith, M. K. (2001) 'David A. Kolb on experiential learning', the encyclopedia of informal education, http://www.infed.org/b-explrn.htm

[23] Wailgum, T. (2008). "SAP skills shortage, CIO," [Retrieved 20 April 2009] http://www.cio.com/article/393663/SAP_Skills_ Shortage Costs SAP s_Customers Partners and Ulti mately_SAP_AG. 